\title{
Topotactic Synthesis of Porous Cobalt Ferrite Platelets from a Layered Double Hydroxide Precursor and their Application in Oxidation Catalysis
}

\author{
Klaus Friedel Ortega, ${ }^{[a]}$ Sven Anke, ${ }^{[b]}$ Soma Salamon, ${ }^{[c]}$ Fatih Özcan, ${ }^{[a]}$ Justus Heese, ${ }^{[a]}$ Corina \\ Andronescu, ${ }^{[d]}$ Joachim Landers, ${ }^{[c]}$ Heiko Wende, ${ }^{[c]}$ Wolfgang Schuhmann, ${ }^{[d]}$ Martin Muhler, ${ }^{[b]}$ Thomas \\ Lunkenbein, ${ }^{*}[\mathrm{e}]$ and Malte Behrens ${ }^{*}[a, f]$
}

\begin{abstract}
Monocrystalline, yet porous mosaic platelets of cobalt ferrite, $\mathrm{CoFe}_{2} \mathrm{O}_{4}$, can be synthesized from a layered double hydroxide (LDH) precursor by thermal decomposition. Using an equimolar mixture of $\mathrm{Fe}^{2+}, \mathrm{Co}^{2+}$ and $\mathrm{Fe}^{3+}$ during co-precipitation, a mixture of $\mathrm{LDH},\left(\mathrm{Fe}^{\prime \prime} \mathrm{Co}^{\prime \prime}\right)_{2 / 3} \mathrm{Fe}^{\prime \prime \prime \prime}{ }_{1 / 3}(\mathrm{OH})_{2}\left(\mathrm{CO}_{3}\right)_{1 / 6} \cdot m \mathrm{H}_{2} \mathrm{O}$, and the target spinel $\mathrm{CoFe}_{2} \mathrm{O}_{4}$ can be obtained in the precursor. During calcination, the remaining $\mathrm{Fe}^{\prime \prime}$ fraction of the $\mathrm{LDH}$ is oxidized to $\mathrm{Fe}^{\mathrm{III}}$ leading to an overall $\mathrm{Co}^{2+}: \mathrm{Fe}^{3+}$ ratio of $1: 2$ as required for spinel crystallization. This pre-adjustment of the spinel composition in the LDH precursor suggests a topotactic crystallization of cobalt ferrite and yields phase pure spinel in unusual anisotropic platelet morphology. The preferred topotactic relationship in most particles is $[111]_{\text {Spinel }}||[001]_{L D H}$. Due to the anion decomposition, holes are formed throughout the quasi monocrystalline platelets. This synthesis approach can be used for different ferrites and the unique microstructure leads to unusual chemical properties as shown by the application of the ex-LDH cobalt ferrite as catalyst in the selective oxidation of 2-propanol. Compared to commercial cobalt ferrite, which mainly catalyzes the oxidative dehydrogenation to acetone, the main reaction over the novel ex-LDH cobalt is dehydration to
\end{abstract}

[a] Dr. Klaus Friedel Ortega, Fatih Özcan, Justus Heese, Prof. Dr. Malte Behrens

Faculty of Chemistry and Center for Nanointegration DuisburgEssen (CENIDE)

University of Duisburg-Essen

Universitätsstr. 7, 45114 Essen, Germany

E-mail: malte.behrens@uni-due.de

[b] Sven Anke, Prof. Dr. Martin Muhle

Laboratory of Industrial Chemistry

Ruhr-University Bochum

Universitätsstr. 150, 44801 Bochum, Germany

[c] Soma Salamon, Dr. Joachim Landers, Prof. Dr. Heiko Wende

Faculty of Physics and CENIDE

University of Duisburg-Essen

Lotharstr. 1, 47057 Duisburg, Germany

[d] Corina Andronescu, Prof. Dr. Wolfgang Schuhmann

Analytical Chemistry - Center for Electrochemical Sciences (CES)

Ruhr-Universität Bochum

Universitätsstr. 150; 44780 Bochum, Germany

[e] Dr. Thomas Lunkenbein

Department of Inorganic Chemistry

Fritz-Haber-Institut der Max-Planck-Gesellschaft

Faradayweg 4-6, 14195 Berlin, Germany

E-mail: lunkenbein@fhi-berlin.mpg.de

[f] Prof. Dr. Malte Behrens,

Ertl Center for Electrochemistry and Catalysis

Gwangju Institute of Science (GIST)

123 Cheomdan-gwagiro (Oryang-dong), Buk-gu, Gwangju 500-712, South Korea

Supporting information for this article is given via a link at the end of the document. propene. Moreover, the OER activity of the ex-LDH catalyst was markedly higher compared to the commercial material.

Cobalt ferrite, $\mathrm{CoFe}_{2} \mathrm{O}_{4}$, is a highly interesting compound due its ferrimagnetic properties, ${ }^{[1]}$ (electro-)chemical reactivity ${ }^{[2]}$ and catalytic activity. ${ }^{[3]}$ For example, recent reports have highlighted the potential of cobalt ferrite as component in multiferroic ceramics, ${ }^{[4]}$ as electrode material in Lithium batteries, ${ }^{[5]}$ and as water oxidation catalyst in electrolysis. ${ }^{[6]}$ Cobalt ferrite is a hopping semi-conductor and crystallizes in an inverse spinel structure, which, due to its cubic symmetry is highly isotropic. The typical habitus of spinel-type crystals are small (truncated) octahedra or cubes. All of the above-mentioned applications can be affected by the morphology and/or size of the cobalt ferrite crystals possibly leading to small diffusion paths, ${ }^{[7]}$ stable magnetic suspensions ${ }^{[8]}$ or exposure of distinct crystal facets. It is thus interesting to control the size and shape of cobalt ferrite crystals during its synthesis. Size control of ferrites has been practiced for instance by micelle approaches leading to small crystallite sizes, but typically isotropic shapes. ${ }^{[9]}$

One effective way to manipulate the shape of oxide particles is their synthesis through the mild thermal decomposition of an anisotropic precursor compound. Oxide particles can be obtained as pseudo-morphs of the decomposable precursor Important examples are layered double hydroxides (LDH), also called hydrotalcite-like materials. LDHs typically crystallize in form of thin hexagonal platelets due to their 2D layered crystal structure and can be easily synthesized with carbonate anions by co-precipitation. Carbonate-LDH have the general composition $\mathrm{M}_{1-x}{ }_{1-x} \mathrm{M}^{\prime \prime \prime}{ }_{x}(\mathrm{OH})_{2}\left(\mathrm{CO}_{3}\right)_{\times / 2} \cdot m \mathrm{H}_{2} \mathrm{O}$. They consist of brucite-like layers $\mathrm{M}^{\mathrm{II/I}}(\mathrm{OH})_{2}$ with edge-sharing $\mathrm{MO}_{6}$ octahedra. The excess positive charges of the $\mathrm{M}^{\mathrm{III}}$ cations are compensated by the carbonate anions in the inter-layer space, where also the crystal water molecules reside. Upon mild calcination of an LDH precursor, the anions decompose at moderate temperature and the resulting oxide particles often retain the anisotropic platelet morphology irrespective of the usually preferred habitus. LDHs can incorporate many different $\mathrm{M}^{2+}$ and $\mathrm{M}^{3+}$ cations and are widely applied in materials chemistry ${ }^{[10]}$ and catalysis, ${ }^{[11]}$ for instance as basic catalysts, ${ }^{[12]}$ electrocatalysts, ${ }^{[13]}$ catalyst precursor materials, ${ }^{[14]}$ or flame retardants. ${ }^{[15]}$

Generally, the formation of a phase-pure spinel from a single LDH precursor is hindered by the compositional incompatibility between precursor and target compound. Stable LDHs require a $\mathrm{M}^{\prime \prime} / \mathrm{M}^{\mathrm{III}}$ ratio between approximately $2: 1$ and $4: 1(0.20 \leq x \leq 0.33)$. Spinels $\mathrm{M}^{\prime \prime} \mathrm{M}^{\prime \prime \prime}{ }_{2} \mathrm{O}_{4}$, however, usually need a $\mathrm{M}^{\prime \prime} / \mathrm{M}^{\prime \prime \prime}$ ratio of $1: 2$. Thus, typically poorly crystalline mixtures of spinel and additional 
$\mathrm{M}$ "O are obtained by LDH calcination, often in form of a nanoscale composite of isotropic primary particles aggregated in form of platelets as for example described in detail for $\mathrm{ZnO} / \mathrm{ZnAl}_{2} \mathrm{O}_{4}$ mixed oxides derived from $\mathrm{Zn}, \mathrm{Al}-\mathrm{LDH} .{ }^{[16]}$ Herein, we report the formation of phase-pure cobalt ferrite from an $\mathrm{LDH}$-containing precursor precipitate in a unique form of monocrystalline, but porous platelets and demonstrate the potential of this new material in the catalytic oxidation of alcohols and water. By comparison with conventional commercial cobalt ferrite, it is shown that the novel ex-LDH cobalt ferrite exhibits unique and interesting properties.

In the proposed co-precipitation synthesis, the above-mentioned compositional constraint was overcome by using a mixture of $\mathrm{Fe}^{2+}$ and $\mathrm{Fe}^{3+}$ for the synthesis of the $\mathrm{LDH}$ precursor at constant $\mathrm{pH}$ value and under the exclusion of air (Fig. S1). The target composition of the co-precipitate was $\mathrm{Fe}_{1 / 3}{ }_{1 / 3} \mathrm{Co}_{1 / 3} \mathrm{Fe}^{\prime \prime \prime}{ }_{1 / 3}(\mathrm{OH})_{2}\left(\mathrm{CO}_{3}\right)_{1 / 6} \cdot m \mathrm{H}_{2} \mathrm{O}$ in accordance with the $\mathrm{M}^{11} / \mathrm{M}^{\mathrm{III}}$ requirement of 2:1 $(x=0.33)$ for LDHs. The presence of the $\mathrm{LDH}$ structure was confirmed by XRD, however a substantial fraction of a spinel by-phase was also detected (Fig. 1a). Rietveld refinement did not show any indication for an additional phase (Tab. S1, S2). The phase composition was 45\% LDH and $55 \%$ spinel. The lattice parameter of the spinel phase was 8.381 (4) $\AA$ and thus very close to $8.3806 \AA$, a value expected for $\mathrm{CoFe}_{2} \mathrm{O}_{4}$, (ICSD No. 98553) as compared to $8.0850 \AA$ for $\mathrm{Co}_{3} \mathrm{O}_{4}$, (ICSD No. 63165) or $8.3941 \AA$ for $\mathrm{Fe}_{3} \mathrm{O}_{4}$ (ICSD No. 26410).
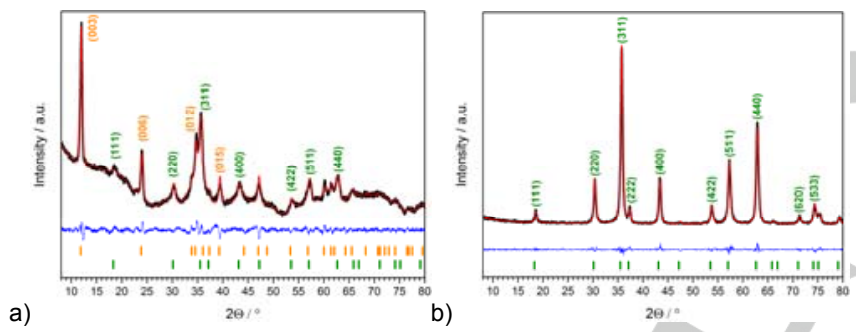

Figure 1. XRD patterns and Rietveld fits of the precursor co-precipitate (a) and of the calcined material (b). The co-precipitate consists of the phase-mixture of $45 \% \mathrm{LDH}$ and $55 \%$ spinel. The calcination product is phase-pure $\mathrm{CoFe}_{2} \mathrm{O}_{4}$ (black: experimental data; red: calculated pattern; blue: difference; orange/green: Bragg peak position of $\mathrm{LDH} / \mathrm{CoFe}_{2} \mathrm{O}_{4}$ ).

We thus conclude that during co-precipitation, washing and drying a significant amount of LDH has already been prematurely transformed into the target spinel phase - likely a result of the imperfect exclusion of air during the two latter steps. Thorough washing was required to remove $\mathrm{Na}$ impurities below a level of $0.05 \%$ as determined by AAS (see SI). SEM micrographs of the co-precipitate further suggest the presence of two different types of material. In addition to the platelet particles of the LDH phase, which exhibit lateral sizes around $0.5-1 \mu \mathrm{m}$ and a thickness of about a few tens of nanometers, also smaller and roundish particles can be observed, tentatively assigned to the spinel by-phase (Fig. S2a). Mössbauer spectra of the precursor support the presence of $\mathrm{CoFe}_{2} \mathrm{O}_{4}$ (Fig. S3). In addition to magnetically ordered $\mathrm{CoFe}_{2} \mathrm{O}_{4}$, a contribution of superparamagnetic $\mathrm{CoFe}_{2} \mathrm{O}_{4}$ crystallites and/or $\mathrm{Fe}^{\text {III }}$ from the $\mathrm{LDH}$ was also detected. At low temperature and high field there is complete magnetic ordering, but strong spin canting indicates low crystallinity of the pre-maturely formed small $\mathrm{CoFe}_{2} \mathrm{O}_{4}$ particles. No clear indication of paramagnetic $\mathrm{Fe}^{l l}$ was detected, ${ }^{[17]}$ which might be a result of the instability of Fe during the relatively long storage time between synthesis and the Mössbauer measurements.

Upon calcination in air, all $\mathrm{Fe}^{\mathrm{Il}}$ is oxidized to Fe $\mathrm{Fe}^{\mathrm{llI}}$, thus fully changing the overall $\mathrm{M}^{\prime \prime} / \mathrm{M}^{\prime \prime \prime}$ ratio from initially $2: 1$ $\left(\left[\mathrm{Fe}^{\| \prime}+\mathrm{Co}^{\| \prime}\right] /\left[\mathrm{Fe}^{\prime \prime \prime}\right]\right)$ to $1: 2$ required for spinel crystallization $\left(\left[\mathrm{Co}^{\prime \prime}\right] /\left[2 \mathrm{Fe}^{\mathrm{III}}\right]\right)$. Calcination at $873 \mathrm{~K}$ leads to a complete decomposition of the precursor (Fig. S4) and indeed yields a phase-pure cobalt ferrite according to XRD (Fig. 1b). Based on a Rietveld refinement of the calcined material, additional crystalline phases can be excluded and the lattice parameter of the $\mathrm{CoFe}_{2} \mathrm{O}_{4}$ was determined as 8.385(13) $\AA$ in good agreement with the literature value and the spinel fraction in the precursor (Fig. S5, Tab. S1, S2). Raman spectroscopy, which is highly sensitive for hematite, also did not show any indication for the presence of impurities (Fig. S6). The superparamagnetic contribution has vanished from the room temperature Mössbauer spectrum indicating $\mathrm{CoFe}_{2} \mathrm{O}_{4}$ crystallite sizes beyond the superparamagnetic limit as a result of calcination (Fig. S3). At low temperature and high field, the expected subspectra of the spinel structure can be distinguished ${ }^{[18]}$ due to a much lower spin-canting compared to the precursor suggesting improved crystallinity of $\mathrm{CoFe}_{2} \mathrm{O}_{4}$. Magnetometry shows the usual behavior of $\mathrm{CoFe}_{2} \mathrm{O}_{4}$ with an increase in the saturation magnetization and coercive field compared to the precursor likely due to the increasing phase fraction and crystallinity as a result of calcination (Fig S7).

SEM investigation of the calcination product show the presence of rather uniform aggregated platelets, which are pseudomorphs of the LDH precursor (Fig. 2a and Fig. S2b). Interestingly, the SEM image clearly shows the presence of intra-particular pores or holes in the individual platelets. These likely have formed during the decomposition of the hydroxide and carbonate anions leading to a shrinkage of the solid. Such "slice of Swiss cheese" morphology is untypical for LDH decomposition into mixtures of $\mathrm{M}^{\mathrm{II}} \mathrm{M}^{\mathrm{II}}{ }_{2} \mathrm{O}_{4}$ and $\mathrm{M}^{\mathrm{II}} \mathrm{O}$ in other systems. While the retention of the platelet morphology is common, shrinkage usually leads to a uniform size reduction of the platelets, and not to the formation of holes. The specific surface area of the ex-LDH CoFe $\mathrm{O}_{4}$ amounts to $31 \mathrm{~m}^{2} \mathrm{~g}^{-1}$ with pore sizes between 2 and $38 \mathrm{~nm}$ in good agreement with Fig. 2 (Fig. S8). It is noted that the small particles assigned to the byphase are still seen as brighter spots in Fig. 2b, but in the SEM images (Fig. 2a and S2b), they are no longer as clearly observed after calcination, which might indicate that the smaller nanoparticles have partially reacted with the larger cobalt ferrite platelets upon heating to $873 \mathrm{~K}$.

The HAADF-STEM image in Figure $2 \mathrm{~b}$ shows the hexagonal shape of a single platelet inherited from the LDH precursor with the holes formed during decomposition and crystallization of the spinel-type cobalt ferrite. Interestingly, high resolution (HR)TEM and selected area electron diffraction (SAED) investigation revealed that individual parts of the holey platelets, which are not covered by spinel impurities are monocrystalline (Fig. 3). In contrast, SAED patterns of aggregates of multiple platelets appear polycrystalline. For single platelets that are covered by spinel nanoparticles, additional spots arise in the otherwise monocrystalline diffraction pattern (Fig. S9a,b). On the nanoscale, the HRTEM images in Fig. 4 show that the porous crystals are composed of a concerted arrangement of mosaic block-like domains that are formed by aligned lattice defects. 
These defects add strain to the sample and may alter their catalytic performance. ${ }^{[19]}$
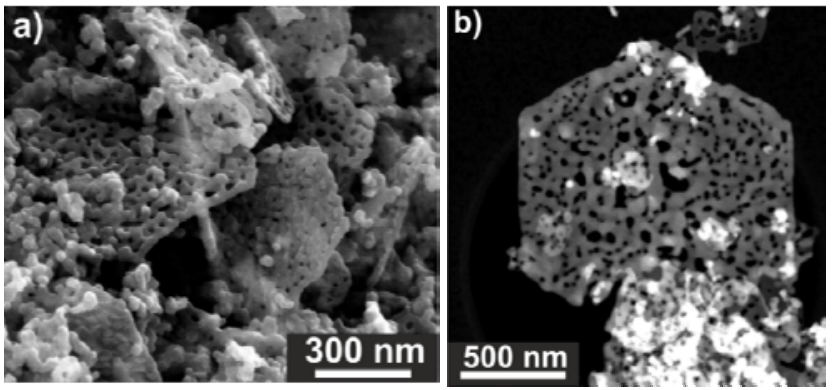

Figure 2. SEM micrograph of the calcined LDH precursor showing aggregates of porous platelets (a) and HAADF-STEM image of one individual platelet (b).

Careful inspection of the HRTEM images shows that the crystalline orientation of the cobalt ferrite platelets remained unchanged even when being interrupted by a pore hole (Fig. 4). In addition, the pore edges as well as the $2 \mathrm{D}$ lattice defects are oriented with respect to each other at distinct angles (e.g., $0^{\circ}$, $60^{\circ}$ or $120^{\circ}$ ), which strengthens the picture of a monocrystalline particle rather than a polycrystalline aggregate. Based on the zone axis of the SAED and the indexing of the Fourier Transform (FT) patterns (Fig. 3, insets), the viewing direction perpendicular to the lateral dimensions is identified as [111] of the spinel lattice for most crystals studied suggesting that 111 facets are the major surface termination. However, at one occasion a [110] zone axis was also observed (Fig. S9c).

The majority of these observations indicate that the thermal decomposition proceeds via a topotactical crystallization of the cobalt ferrite, where the [111] zone axis is preferably related to the c-axis of the LDH, which is the stacking axis of the layers oriented perpendicular to the lateral dimensions of the platelets: $[111]_{\text {spinel }}||[001]_{\mathrm{LDH}}$. A topotactic crystallization mechanism of oxides formed from LDHs during calcination has been proposed. ${ }^{[20]}$ However, due to poor crystallinity and multiple phases of the decomposition product, it turned out to be difficult to establish a clear topotactic crystallization in a straightforward manner for other LDH precursors.

We propose that the unique microstructure and morphology of the ex-LDH CoFe $\mathrm{O}_{4}$ is related to the successful pre-adjustment of the cationic composition in the precursor. Using the LDH approach, the cations are initially located in an atomically perfect distribution in the solid solution type precursor. Upon oxidation of $\mathrm{Fe}^{\mathrm{II}}$, also the proper ratio of $\mathrm{M}^{\prime \prime} / \mathrm{M}^{\mathrm{III}}$ is pre-adjusted throughout the whole solid. Under these conditions, not met in conventional $\mathrm{LDHs}$ without oxidizable $\mathrm{Fe}$ ", crystallization of the $\mathrm{CoFe}_{2} \mathrm{O}_{4}$ requires hardly any solid-state diffusion of the cations and can proceed readily in a topotactic manner preferably under retention of the orientation of the close-packed oxygen layers in (001) in the trigonal LDH and (111) in the cubic spinel, respectively. In particular, no phase segregation is required as a single oxide phase can be formed. This easy crystallization of the thermally stable spinel phase presumably leads to the early formation of an oxide backbone in the typically not favored anisotropic platelet form and to the formation of holey pores as the anions decompose and $\mathrm{H}_{2} \mathrm{O}$ and $\mathrm{CO}_{2}$ diffuse out of the solid. It is noted that mesoporous single crystals of spinel-type $\mathrm{Co}_{3} \mathrm{O}_{4}$ are accessible via a closely related route by topotactic crystallization from brucite-type $\mathrm{Co}(\mathrm{OH})_{2}$ precursors and found to be highly interesting electrode materials for lithium ion batteries. ${ }^{[21]}$ We highlight that our synthesis procedure yields binary mixed spinels and is based on the utilization of mixed $\mathrm{Fe}^{2+}$ and $\mathrm{Fe}^{3+}$ solutions and that it should be generally applicable for the synthesis of many kinds of ferrite spinels by combination of $\mathrm{Fe}^{2+} / \mathrm{Fe}^{3+}$ with various $\mathrm{LDH}$-forming cations $\mathrm{M}^{2+}$. For instance, we have recently reported ex-LDH $\mathrm{MgFe}_{2} \mathrm{O}_{4}$ spinels as precursors for $\mathrm{Fe}$-based catalysts in ammonia synthesis and decomposition. ${ }^{[22]}$ If synthesized from a $\mathrm{Fe}_{1 / 3}{ }_{1 / 3} \mathrm{Mg}_{1 / 3} \mathrm{Fe}^{\prime \prime \prime \prime}{ }_{1 / 3}(\mathrm{OH})_{2}\left(\mathrm{CO}_{3}\right)_{1 / 6} \cdot \mathrm{mH}_{2} \mathrm{O}$ LDH precursor, holey platelets of the resulting $\mathrm{MgFe}_{2} \mathrm{O}_{4}$ can be found by SEM also in this material (Fig. S10), showing the versatility of the proposed synthesis approach.

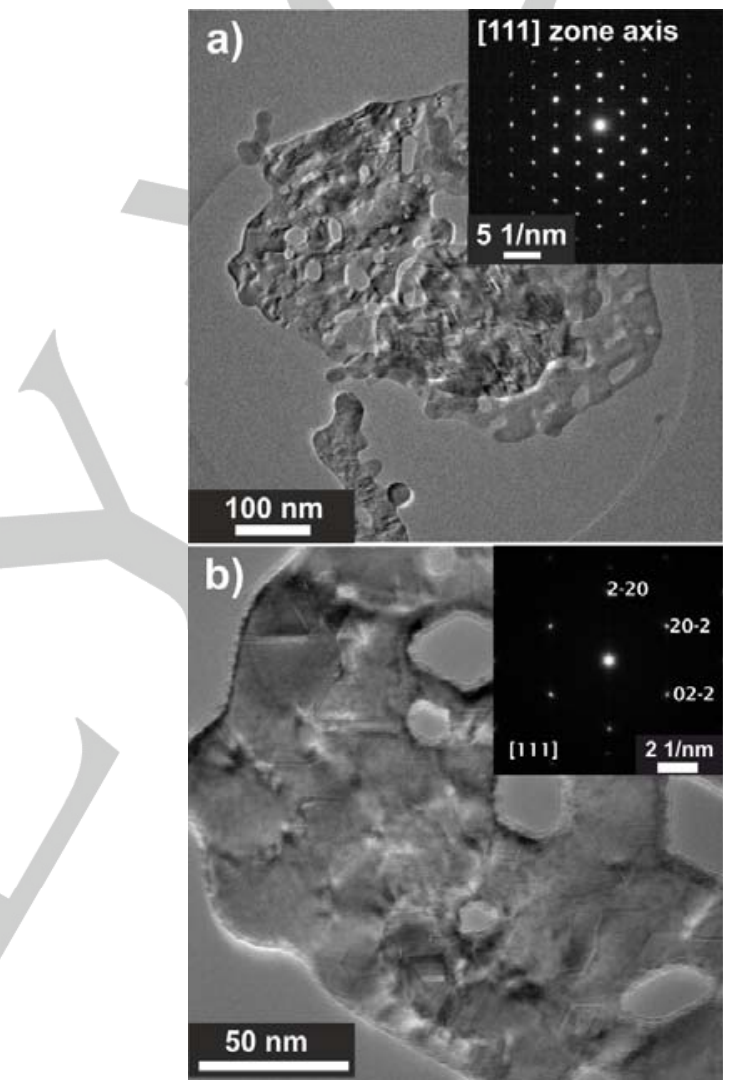

Figure 3. TEM image of a porous $\mathrm{CoFe}_{2} \mathrm{O}_{4}$ platelet (a) and corresponding SAED pattern (inset), HRTEM image of the edge region of such a platelet (b) and corresponding FT with indexing of the cubic spinel structure and zone axis [111] (inset).

To demonstrate that the unique structural properties of the ex$\mathrm{LDH} \mathrm{CoFe} \mathrm{O}_{4}$ are related to interesting chemical properties, we here briefly introduce two application examples to compare the new material to commercial $\mathrm{CoFe}_{2} \mathrm{O}_{4}$ (purchased from SigmaAldrich). Cobalt ferrite is known as an oxidation catalyst showing high activity, e.g., in the electrocatalytic oxygen evolution reaction $(\mathrm{OER}),{ }^{[23]}$ in the gas phase oxidation of $\mathrm{CO}^{[3]}$ or in the selective oxidation of terpenes. ${ }^{[24]}$ We have used the ex-LDH $\mathrm{CoFe}_{2} \mathrm{O}_{4}$ and commercial $\mathrm{CoFe}_{2} \mathrm{O}_{4}$ in the temperatureprogrammed oxidation of 2-propanol and in the OER. It is noted that neither XRD nor $\mathrm{N}_{2}$ physisorption revealed major differences in the crystallinity or specific surface area of the two 
catalysts that could easily explain large differences in catalysis (Fig. S8, S11).

The results of the 2-propanol oxidation experiments are shown in Figure 5 and Table S3. The commercial catalyst exhibits a higher activity at low temperatures in the first heating cycle. Upon cooling back down, however, the temperature profile of the 2-propanol conversion is very similar for both catalysts (gray open symbols in Fig. 5) in agreement with the similar specific surface area. It remained almost unchanged in further heating cycles (Fig. S12). Interestingly, at $573 \mathrm{~K}$ the conversion in 2propanol is similar for both catalysts, while the oxygen conversion and the product selectivity are markedly different. The commercial material is highly selective to acetone indicating that the oxidative dehydrogenation (1) is the major reaction over this catalyst. This agrees with the conversion in oxygen reaching similar values like that in alcohol. Contrarily, the major product over the ex-LDH catalyst is propene (52\% selectivity), indicating that the dehydration reaction (2) is favored over this catalyst. The selectivity to acetone was $40 \%$, which corresponds roughly to the conversion in oxygen. Only little total oxidation (3) was observed in both cases and the extent was lesser for the exLDH catalyst.

$$
\begin{array}{ll}
2 \mathrm{C}_{3} \mathrm{H}_{7} \mathrm{OH}+\mathrm{O}_{2} \rightarrow & 2 \mathrm{C}_{3} \mathrm{H}_{6} \mathrm{O}+2 \mathrm{H}_{2} \mathrm{O} \\
\mathrm{C}_{3} \mathrm{H}_{7} \mathrm{OH}\left(+\mathrm{O}_{2}\right) \rightarrow & \mathrm{C}_{3} \mathrm{H}_{6}+\mathrm{H}_{2} \mathrm{O} \\
2 \mathrm{C}_{3} \mathrm{H}_{7} \mathrm{OH}+9 \mathrm{O}_{2} & \rightarrow \quad 6 \mathrm{CO}_{2}+8 \mathrm{H}_{2} \mathrm{O}
\end{array}
$$

These findings suggest differences in acid-base or redox properties of the cobalt ferrite surface in the two catalysts. The dehydration activity of 2-propanol over metal oxides towards propylene is affected by the number, the nature, and the strength of acid sites. ${ }^{[25]}$ In contrast, the dehydrogenation pathway yielding acetone through a concerted mechanism over acid-base pairs proceeds independent of their intrinsic strength. Furthermore, the nature of the metal oxide and the carrier gas type can modify the product selectivities. ${ }^{[26]}$ In case of $\mathrm{NiFe}_{2} \mathrm{O}_{4}$, significant differences in the product distribution have been linked to variations in the $\mathrm{Ni} / \mathrm{Fe}$ surface ratio. ${ }^{[27]}$

The OER experiments for the ex-LDH and commercial $\mathrm{CoFe}_{2} \mathrm{O}_{4}$ are presented in Figure 6. The ex-LDH $\mathrm{CoFe}_{2} \mathrm{O}_{4}$ shows higher catalytic activity towards OER, a current density of $10 \mathrm{~mA} \mathrm{~cm}{ }^{-2}$ being reached at just $0.43 \mathrm{~V}$ overpotential, while for the commercial $\mathrm{CoFe}_{2} \mathrm{O}_{4}, 0.59 \mathrm{mV}$ overpotential is required to reach the same current density. Ex-LDH $\mathrm{CoFe}_{2} \mathrm{O}_{4}$ shows also a lower Tafel slope $(57 \mathrm{mV} / \mathrm{dec})$ as compared with the commercial material $(128 \mathrm{mV} / \mathrm{dec})$ which indicates that the electron transfer is facilitated in the case of the ex-LDH material. The slope of the current curve in Figure 6 a suggests a higher conductivity of the mono-crystalline platelets, which likely is an important contribution to the electocatalytic activity. Stability measurements (Fig. S13) did not indicate decay of the activity or severe structural changes of the particles at the electrode during OER (Fig. S14).

For a full explanation of the different catalytic performances, a detailed study of the surface chemistry is required, which is beyond the scope of the present communication. In addition to the preferred 111 termination and the unique morphology, also alkaline residues such as surface $\mathrm{OH}$ groups or surface segregation might play a role here. However, first HR scanning TEM images of the surface region of the ex-LDH are shown in
Figure S9c and show high crystallinity not suggesting severe surface segregation.
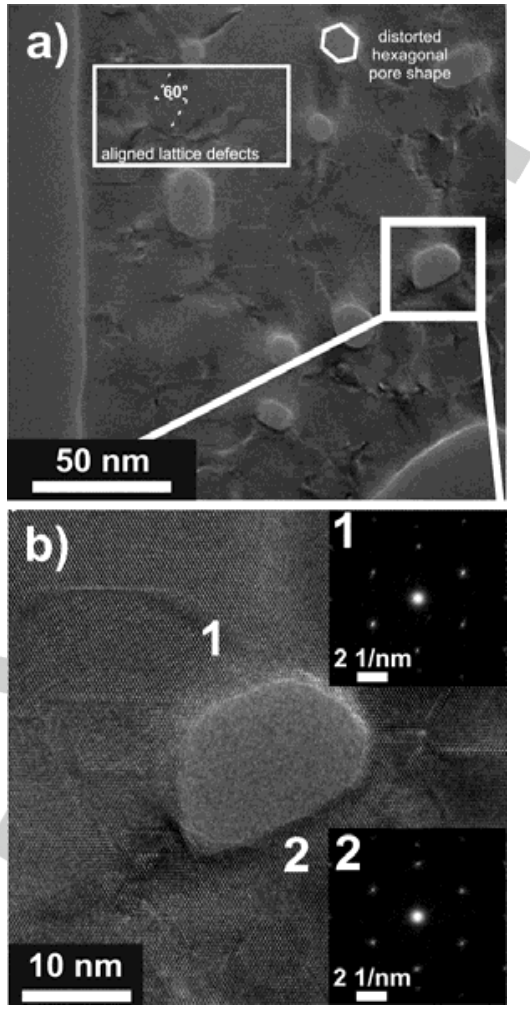

Figure 4. HRTEM image of a $\mathrm{CoFe}_{2} \mathrm{O}_{4}$ platelet showing a region with many aligned lattice defects and the distorted hexagonal shape of the holey pores. The zoom in the lower panel (b) shows the crystalline surrounding of one pore and the undisturbed monocrystalline ordering at both sides of the hole (compare FT 1 and 2).
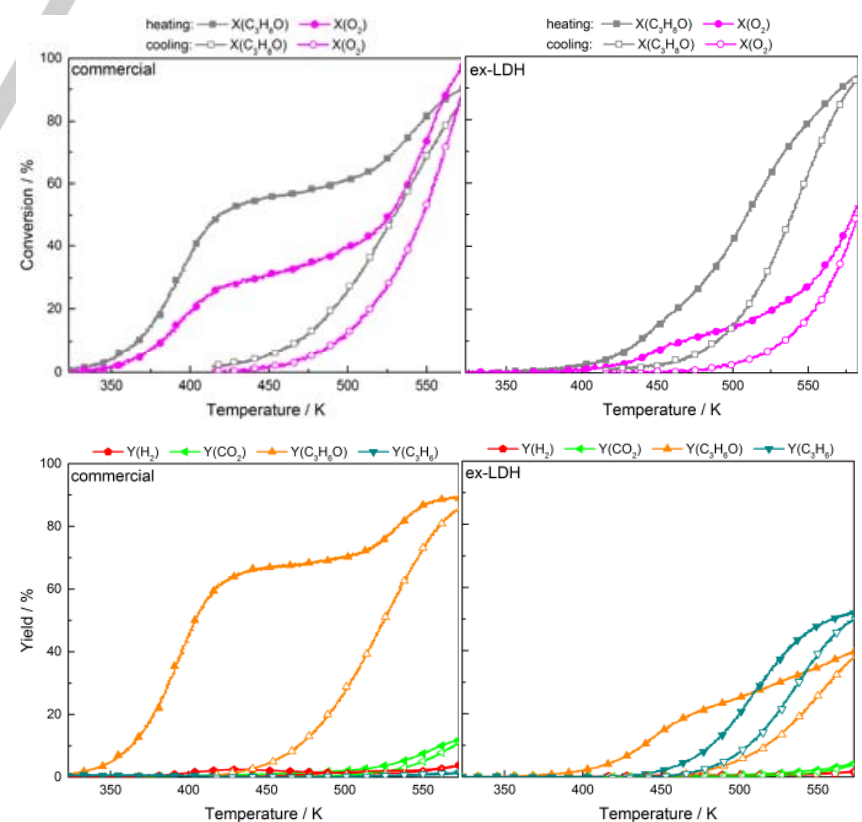

Figure 5. Conversions (upper panels) and yields (lower panels) of the commercial $\mathrm{CoFe}_{2} \mathrm{O}_{4}$ (left hand panels) and ex- $\mathrm{LDH} \mathrm{CoFe} \mathrm{O}_{4}$ (right hand panels) upon heating (closed symbols) and cooling (open symbols) in the oxidation of 2-propanol as a function of temperature. 
In summary, the synthetic approach reported herein provides access to porous ferrites with for well-crystalline spinels relatively high porosity. In catalysis, such anisotropic materials may bridge the gap between model catalysts with low surface area and structurally highly complex real-world catalysts. They, therefore, exhibit potential to contribute to a better understanding in heterogeneous oxidation catalysis. To a first approximation, the differences in catalytic properties reported here seem to be best explained by different acid/base properties, surface terminations and conductivity, but further work on these questions is required, and is currently under way in our labs. One specific aim is to fully control the topotacticity. In addition to heterogeneous oxidation catalysis, these novel materials may also play an important role in many other fields of materials chemistry, in which ferrites are used, acting as a promising materials basis for studying the role of particle anisotropy. ${ }^{[21 d]}$
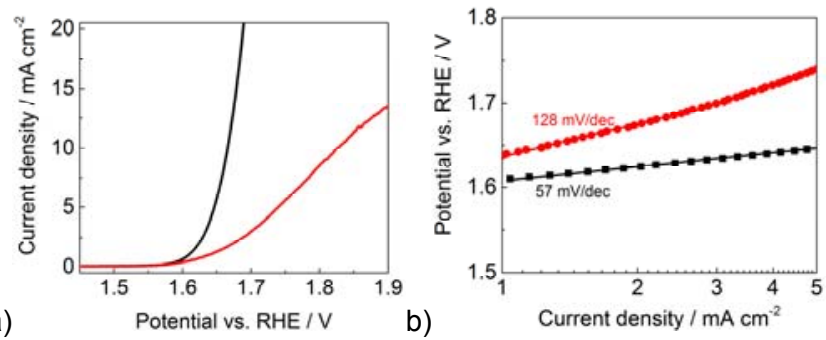

Figure 6. Linear sweep voltammograms (a) and Tafel slopes (b) of commercial $\mathrm{CoFe}_{2} \mathrm{O}_{4}$ (red) and ex-LDH $\mathrm{CoFe}_{2} \mathrm{O}_{4}$ (black) recorded in $\mathrm{O}_{2}$-saturated $\mathrm{KOH}$ $(1 \mathrm{M})$ at a scan rate of $5 \mathrm{mV} \mathrm{s}^{-1}$ and $1600 \mathrm{rpm}$.

\section{Experimental Section}

All experimental details are compiled in the supporting information.

\section{Acknowledgements}

This work was supported by Stiftung Mercator (MERCUR) and by the DFG within the SPPs 1681 (WE2623/7-1), 1613 (BE4767/2-2) and FOR 1509 (WE2623/13). We thank D. Drescher, A. Servas, C. Stienen and A. Gehlhaar for their help with the experimental work. Prof. S. Schulz, Prof. M. Epple and Prof. M. Winterer of the University of Duisburg-Essen are gratefully acknowledged for allocating access to their characterization facilities.

Keywords: Cobalt Ferrite $•$ Layered Double Hydroxide • Topotactic Transformations • Selective Alcohol Oxidation • Water Oxidation

[1] C. N. Chinnasamy, M. Senoue, B. Jeyadevan, O. Perales-Perez, K Shinoda, K. Tohji, Journal of Colloid and Interface Science 2003, 263, 80-83.

[2] P. Lavela, J. L. Tirado, Journal of Power Sources 2007, 172, 379-387.
[3] C. A. Chagas, E. F. De Souza, M. C. N. A. De Carvalho, R. L. Martins, M. Schmal, Applied Catalysis A: General 2016, 519, 139-145

[4] M. Etier, Y. Gao, V. V. Shvartsman, A. Elsukova, J. Landers, H. Wende D. C. Lupascu, Ferroelectrics 2012, 438, 115-122.

[5] S. Permien, S. Indris, U. Schürmann, L. Kienle, S. Zander, S. Doyle, W. Bensch, Chemistry of Materials 2016, 28, 434-444.

[6] T. Grewe, X. Deng, H. Tüysüz, Chemistry of Materials 2014, 26, 31623168.

[7] P. G. Bruce, B. Scrosati, J.-M. Tarascon, Angewandte Chemie 2008 120, 2972-2989.

[8] S. Amiri, H. Shokrollahi, Materials Science and Engineering: C 2013, 33, 1-8.

[9] A. H. Lu, E. L. Salabas, F. Schüth, Angewandte Chemie - International Edition 2007, 46, 1222-1244.

[10] a) D. G. Evans, X. Duan, Chemical Communications 2006, 485-496; b) V. Rives, M. del Arco, C. Martín, Applied Clay Science 2014, 88-89, 239-269.

[11] C. Li, M. Wei, D. G. Evans, X. Duan, Small 2014, 10, 4469-4486.

[12] G. Fan, F. Li, D. G. Evans, X. Duan, Chemical Society Reviews 2014, 43, 7040-7066.

[13] F. Yang, K. Sliozberg, I. Sinev, H. Antoni, A. Bähr, K. Ollegott, W. Xia, J. Masa, W. Grünert, B. R. Cuenya, W. Schuhmann, M. Muhler, ChemSusChem 2017, 10, 156-165.

[14] a) M. Behrens, I. Kasatkin, S. Kühl, G. Weinberg, Chemistry of Materials 2010, 22, 386-397; b) K. Mette, S. Kühl, H. Düdder, K. Kähler A. Tarasov, M. Muhler, M. Behrens, ChemCatChem 2014, 6, 100-104.

[15] A. Edenharter, P. Feicht, B. Diar-Bakerly, G. Beyer, J. Breu, Polymer (United Kingdom) 2016, 91, 41-49.

[16] X. Zhao, F. Zhang, S. Xu, D. G. Evans, X. Duan, Chemistry of Materials 2010, 22, 3933-3942.

[17] L. Simon, M. François, P. Refait, G. Renaudin, M. Lelaurain, J.-M. R. Génin, Solid State Sciences 2003, 5, 327-334.

[18] A. Bouhas, M. Amzal, B. Zouranen, Materials Chemistry and Physics 1993, 33, 80-84

[19] K. Amakawa, L. Sun, C. Guo, M. Hävecker, P. Kube, I. E. Wachs, S Lwin, A. I. Frenkel, A. Patlolla, K. Hermann, R. Schlögl, A. Trunschke Angewandte Chemie International Edition 2013, 52, 13553-13557.

[20] a) D. G. Costa, A. B. Rocha, W. F. Souza, S. S. X. Chiaro, A. A. Leitão, Journal of Physical Chemistry C 2012, 116, 13679-13687; b) S. Zhang Y. Dou, J. Zhou, M. Pu, H. Yan, M. Wei, D. G. Evans, X. Duan, ChemPhysChem 2016, 2754-2766; c) L. Markov, K. Petrov, A. Lyubchova, Solid State Ionics 1990, 39, 187-193.

[21] a) L. Tian, H. Zou, J. Fu, X. Yang, Y. Wang, H. Guo, X. Fu, C. Liang, M. Wu, P. K. Shen, Q. Gao, Advanced Functional Materials 2010, 20, 617623; b) J. Wang, G. Du, R. Zeng, B. Niu, Z. Chen, Z. Guo, S. Dou Electrochimica Acta 2010, 55, 4805-4811; c) X. Duan, J. Ji, X. Yan, G. Qian, D. Chen, X. Zhou, ChemCatChem 2016, 8, 938-945; d) D. Su, S Dou, G. Wang, Scientific Reports 2014, 4.

[22] K. F. Ortega, D. Rein, C. Lüttmann, J. Heese, F. Özcan, M. Heidelmann J. Folke, K. Kähler, R. Schlögl, M. Behrens, ChemCatChem 2017, 9 659-671.

[23] K. Chakrapani, G. Bendt, H. Hajiyani, I. Schwarzrock, T. Lunkenbein, S Salamon, J. Landers, H. Wende, R. Schlögl, R. Pentcheva, M. Behrens, S. Schulz, ChemCatChem 2017, n/a-n/a.

[24] L. Menini, M. C. Pereira, L. A. Parreira, J. D. Fabris, E. V. Gusevskaya Journal of Catalysis 2008, 254, 355-364.

[25] A. Gervasini, A. Auroux, J. Catal. 1991, 131, 190-198.

[26] A. Gervasini, J. Fenyvesi, A. Auroux, Catal. Lett. 1997, 43, 219-228.

[27] R. Benrabaa, H. Boukhlouf, S. Barama, E. Bordes-Richard, R. N Vannier, A. Barama, Catal. Lett. 2012, 142, 42-49. 
Entry for the Table of Contents (Please choose one layout)

Layout 1:

\section{FULL PAPER}

Text for Table of Contents
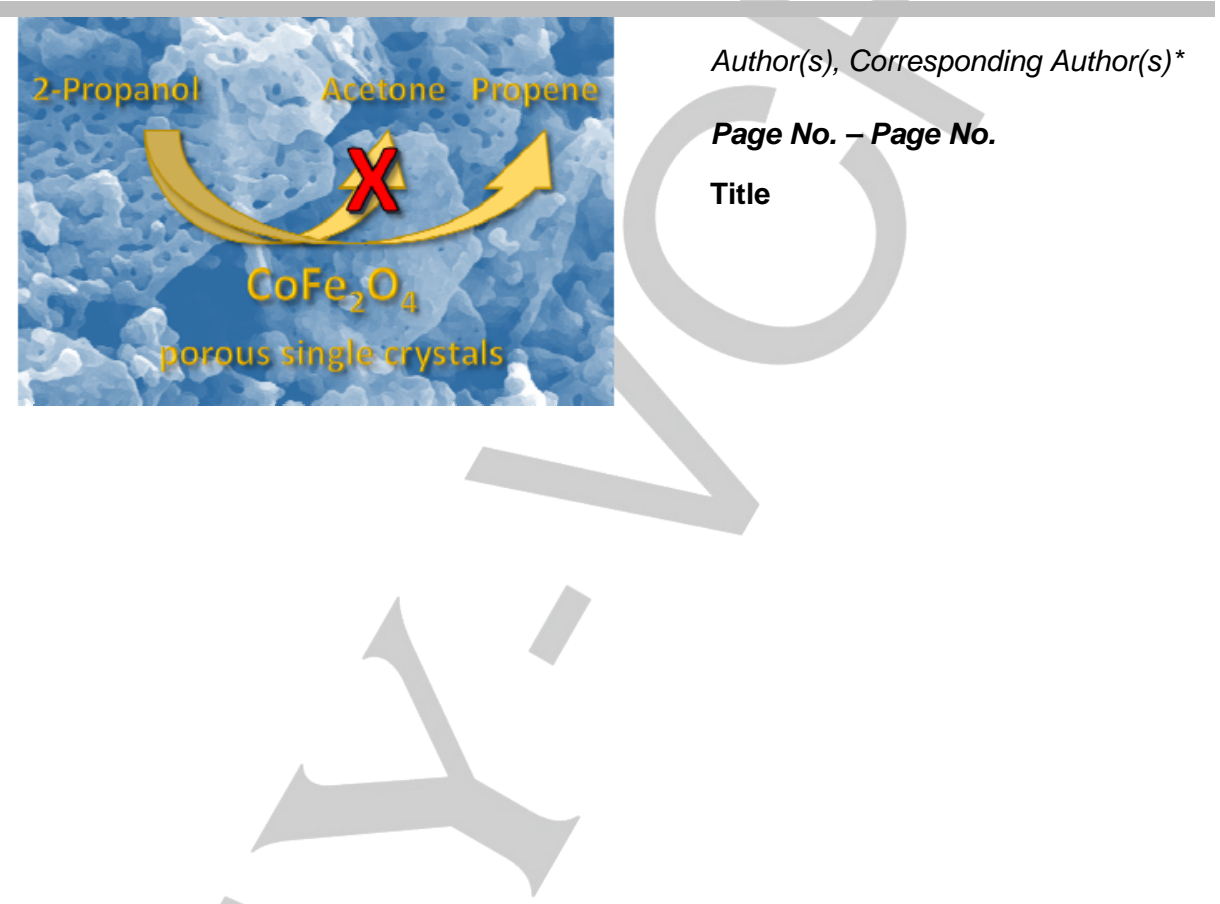